Portland State University

PDXScholar

May 10th, 11:00 AM - 1:00 PM

\title{
Extended Saleh Model for Behavioral Modeling of Envelope Tracking Power Amplifiers
}

\author{
Haider Al Kanan \\ Portland State University \\ Fu Li \\ Portland State University \\ Felice Francesco Tafuri \\ Aalborg University
}

Follow this and additional works at: https://pdxscholar.library.pdx.edu/studentsymposium

Part of the Electrical and Computer Engineering Commons

Let us know how access to this document benefits you.

Al Kanan, Haider; Li, Fu; and Tafuri, Felice Francesco, "Extended Saleh Model for Behavioral Modeling of Envelope Tracking Power Amplifiers" (2017). Student Research Symposium. 23.

https://pdxscholar.library.pdx.edu/studentsymposium/2017/posters/23

This Poster is brought to you for free and open access. It has been accepted for inclusion in Student Research Symposium by an authorized administrator of PDXScholar. Please contact us if we can make this document more accessible: pdxscholar@pdx.edu. 


\title{
Extended Saleh Model for Behavioral Modeling Envelope Tracking Power Amplifiers
}

\author{
Haider Al-kanan ${ }^{1}, \mathrm{Fu} \mathrm{Li}^{1}$, Felice Francesco Tafuri ${ }^{2}$ \\ ${ }^{1}$ Portland State University, ${ }^{2}$ Aalborg University
}

\section{Introduction}

Envelope Tracking (ET) is one of the most deployed efficiency enhancement techniques to improve efficiency of RF Power Amplifiers (PAs) in wireless communication. The problem is that state-of-the-art behavioral models for fixed supply PAs are not accurate enough to model the peculiar distortion effects induced by the time-varying supply regime induced by the ET operation mode.

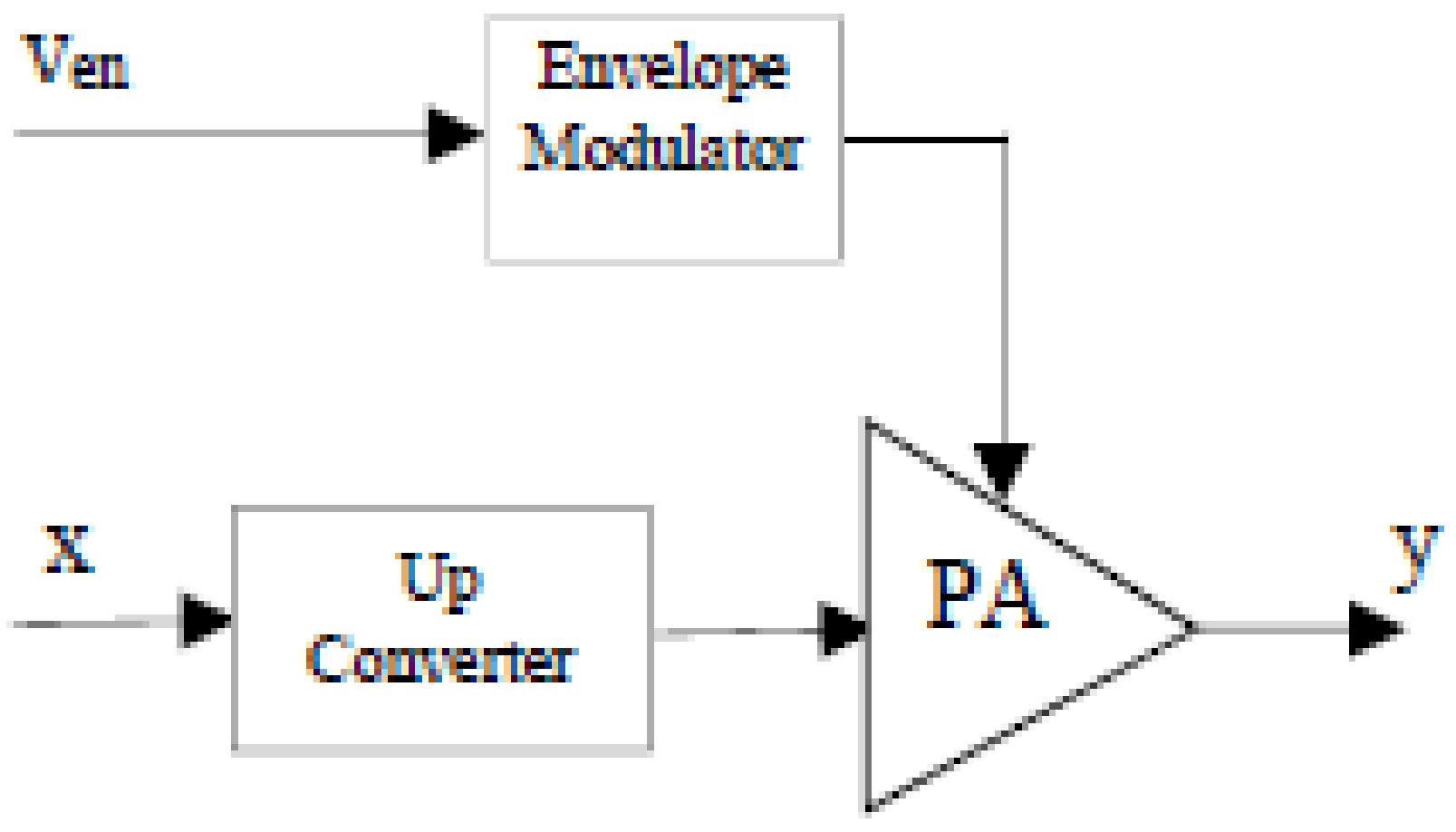

Fig. 1. Simplified block diagram of an equivalen baseband three-port model for ET PAs. $\mathrm{V}_{\mathrm{en}}$ is the modulated supply voltage obtaining by shaping the envelope of the ET PA input baseband signal x.

\section{Modeling results}

10000 samples of complex baseband input, output, and envelope signals are used for model coefficients extraction. A Least Square Error (LSE) method can be iteratively used for all model coefficient extraction. The modeling accuracy is evaluated in the time domain based on the Normalized Mean Square Error (NMSE), and in the frequency domain based on the Adjacent Channel Error Power Ratio (ACEPR). NMSE and ACEPR versus the nonlinear order and memory depth of the AM/PM Taylor model are depicted in Fig. 4. Fig. 5 - 6 represent the comparison of simulation data and behavioral modeled data in terms of gain, phase deviation and power spectral density for optimal values of the model parameters. The proposed model can mimic ET specific dynamic distortion memory effect as shown in both $\mathrm{AM} / \mathrm{AM}$ and $\mathrm{AM} / \mathrm{PM}$ characteristics.

\section{Objectives}

The objectives of this work are:

- Present a new accurate behavioral model for ET PAs

- Include ET-specific dynamic AM/AM and $\mathrm{AM} / \mathrm{PM}$ distortion effects in the presented model

- A linearization algorithm based on the presented model can be derived to perform digital predistortion of ET PAs

\section{Extended Saleh model}

The proposed model extends the Saleh model for fixed supply RF PAs by inserting the modulated supply voltage as an additional model variable (Fig. 1). Memory effects in both AM/AM and AM/PM characteristics are modeled using respectively a Finite Impulse Response (FIR) filter and Taylor polynomial with memory (Fig. 2).

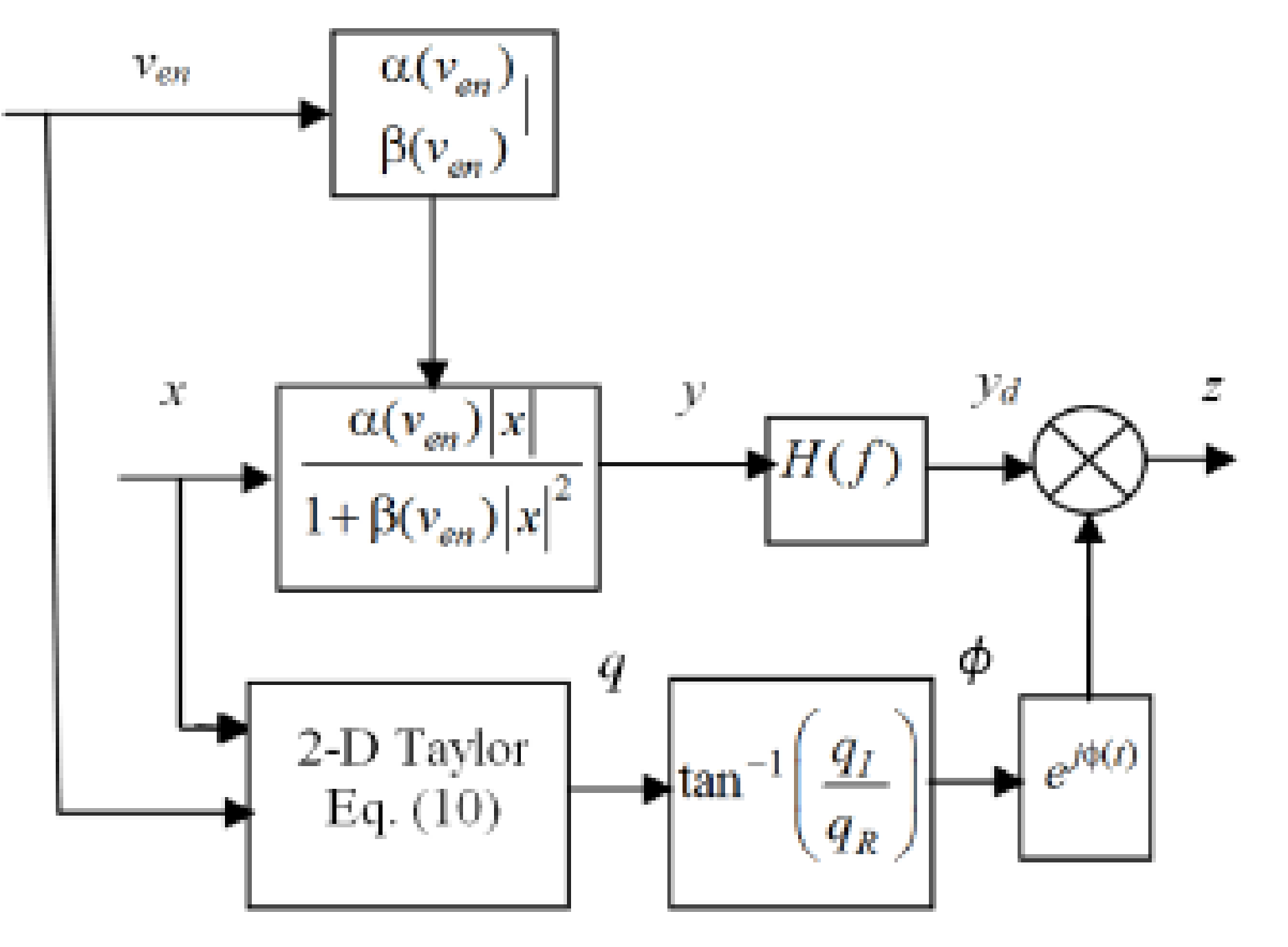

Fig. 2. Block diagram of extended Saleh model for ET PAs proposed in this work

$$
\begin{gathered}
y=\frac{\alpha\left(v_{m}\right)|x|}{1+\beta\left(v_{m}\right)|x|^{2}} \\
\alpha\left(v_{e n}\right)=\sum_{i=1}^{N_{A}} \alpha_{i} v_{e n}^{i} \\
\beta\left(v_{e n}\right)=\sum_{i=1}^{N_{B}} \beta_{i} v_{e n}^{i} \\
y_{d}[n]=\sum_{k=0}^{M_{A M}} h[k] y[n-k]
\end{gathered}
$$
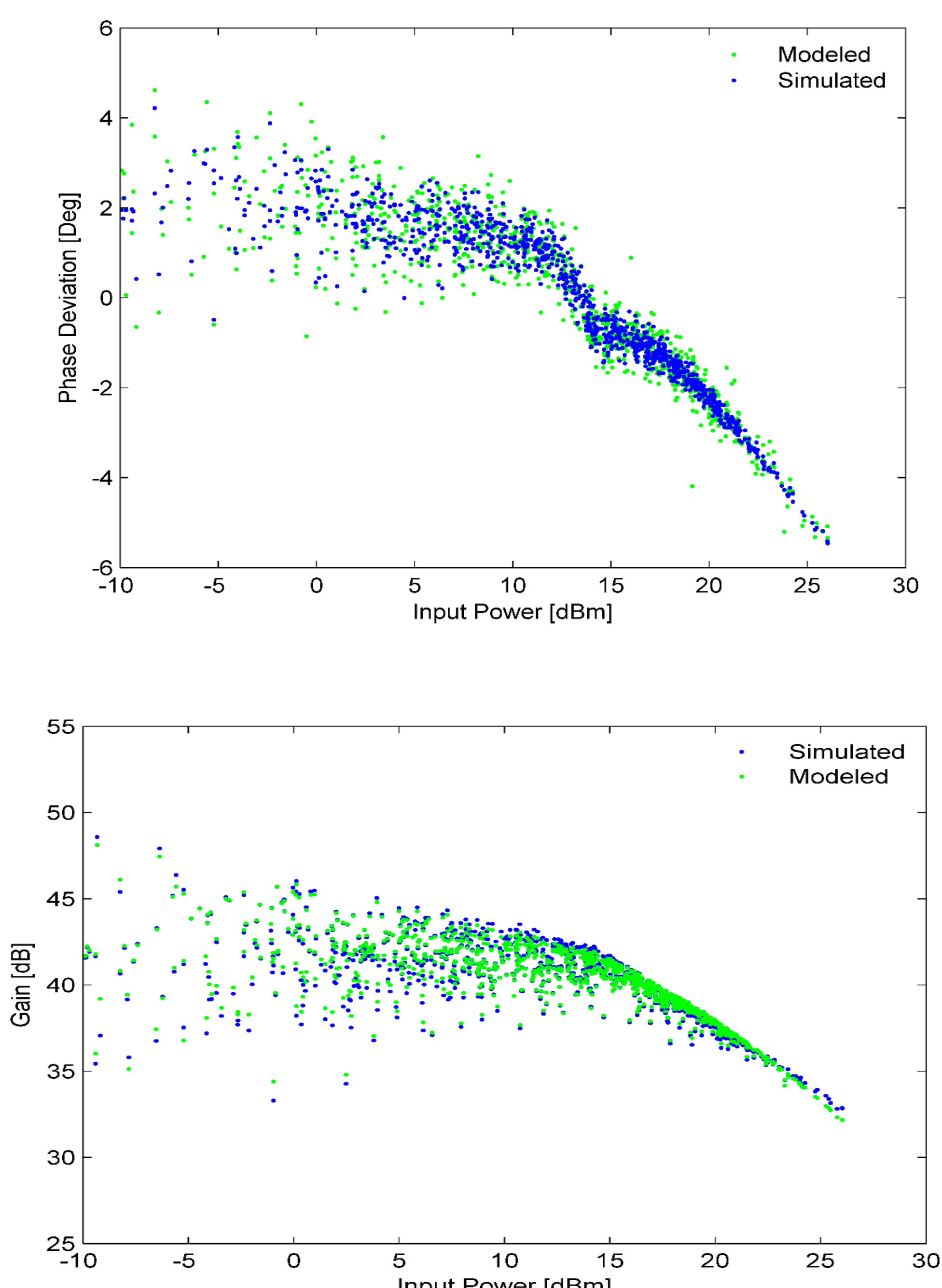

Fig. 5. Gain and phase deviation of the ET PA simulated in ADS and the proposed extended Saleh model. The Extended Saleh model simulations are obtained for $\mathrm{N}_{\mathrm{A}}=2, \mathrm{~N}_{\mathrm{B}}=1, \mathrm{M}_{\mathrm{AM}}=5, \mathrm{~N}=9, \mathrm{Q}=7, \mathrm{M}=12$.

$$
q(n)=\sum_{k=0}^{Q} \sum_{j=0}^{N} \sum_{m=0}^{M} P_{(k, j, m)} x^{j}(n-m) v_{e n}^{k}(n-m)
$$

\section{Simulation environment}

The proposed model is validated and evaluated in MATLAB by using simulation data produced in Advanced Design System (ADS). The ADS schematic is depicted in Fig .3. ADS simulations are based on LTE downlink signal of $5 \mathrm{MHz}$ bandwidth.

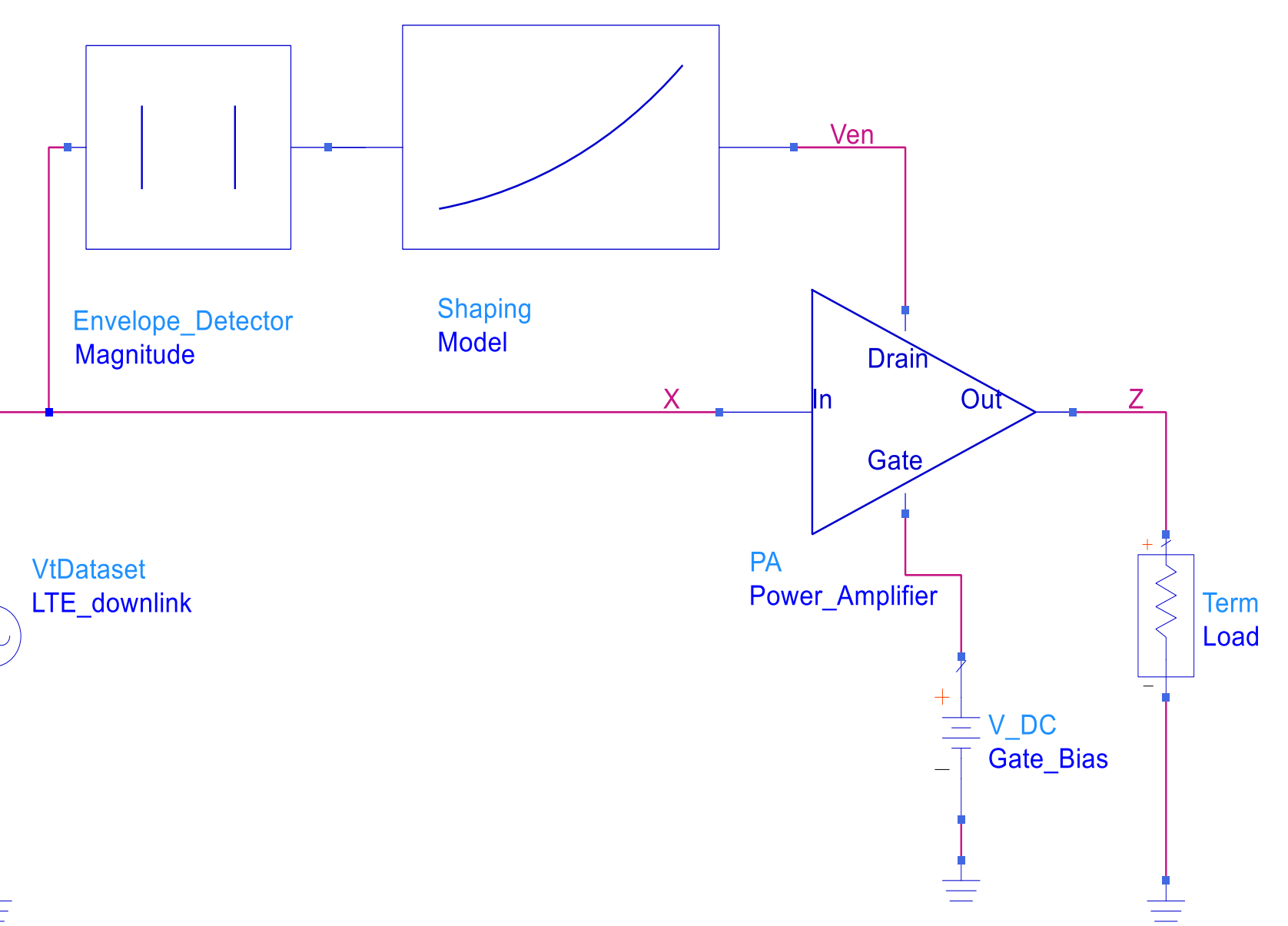

Fig. 3. Circuit schematic used for the simulation of the ET PA using Advanced Design System (ADS).

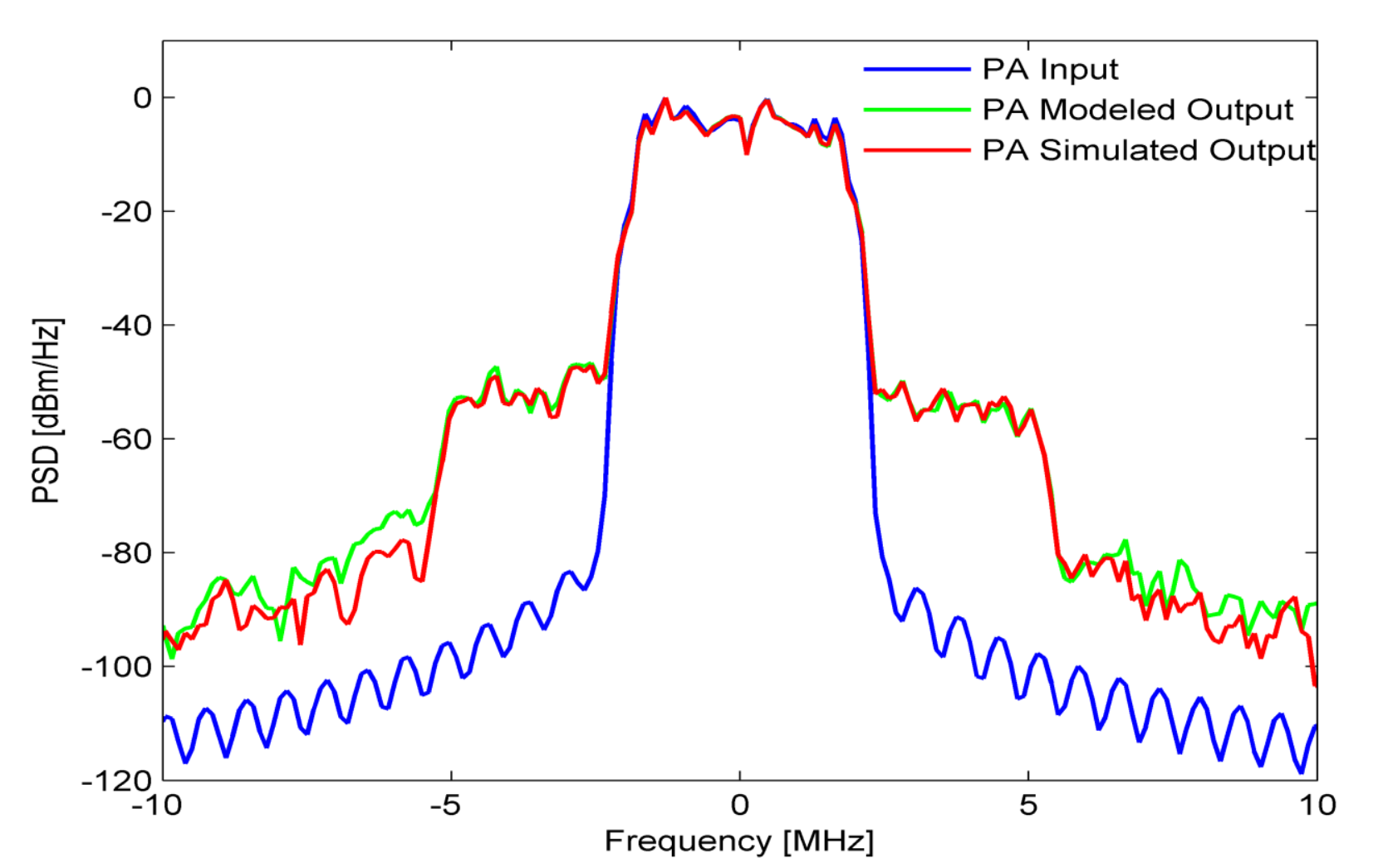

Fig. 6. Power spectral density (PSD) of the ET PA simulated in ADS and the proposed extended Saleh model. The Extended Saleh model simulations are obtained for $\mathrm{N}_{\mathrm{A}}=2, \mathrm{~N}_{\mathrm{B}}=1, \mathrm{M}_{\mathrm{AM}}=5, \mathrm{~N}=9, \mathrm{Q}=7, \mathrm{M}=12$.

\section{Conclusion}

Fig. 4. NMSE and ACEPR versus nonlinear orders $\mathrm{N}$ an $\mathrm{Q}$ of the AM/PM Taylor model. The Extended Sale model simulations are obtained for $\mathrm{N}_{\mathrm{A}}=2, \mathrm{~N}_{\mathrm{B}}=1, \mathrm{M}_{\mathrm{AM}}=5$, $\mathrm{M}=12$
A new behavioral model was proposed by extension of a static Saleh model for PA.

The model parameters have been swept to evaluate the model performance.

- NMSE of - 44.6 dB and ACEPR of $53.7 \mathrm{~dB}$ were observed as modeling best performance. 